\title{
Comparison of long term evolution of adult onset and juvenile onset Still's disease, both followed up for more than 10 years
}

Jean Cabane, Agnès Michon, Jean-Marc Ziza, Pierre Bourgeois, Olivier Blétry, Pierre Godeau, Marcel-Francis Kahn

\begin{abstract}
Still's disease is a clinical entity of unknown origin, which can appear before 15 years of age (juvenile onset Still's disease) or later (adult onset Still's disease). There are few reported data about the long term prognosis of Still's disease and no study compares the long term evolution of adult onset and juvenile onset Still's disease. Eighteen patients fulfilling the American Rheumatism Association criteria for Still's disease were followed up for more than 10 years. Ten (group 1) had juvenile onset Still's disease and eight (group 2) adult onset Still's disease.
\end{abstract}

A comparison of the groups showed no significant differences in the initial systemic manifestations of Still's disease, or in the joint lesions. Both groups had severe sequelae, which appeared between six and 10 years after the initial flare up of Still's disease. Nine patients had articular damage and nine had only arthritis without apparent $x$ ray abnormalities. Nine patients had bilateral hip destruction in less than four years. Of these nine, seven required 13 total hip replacements before the age of $\mathbf{4 5}$. In the whole group of 18 patients bilateral involvement of the following joints was also seen: carpus (seven patients), knee (four), tarsus (four), ankle (three); three patients had ankylosis of the cervical spine.

The occurrence of amyloidosis (three cases, two deaths) was restricted to group 2. This was the only difference between the groups, as the treatments were identical.

It is concluded that the articular prognosis of Still's disease is poor, be it adult onset or juvenile onset, with severe joint destruction in half of the patients.

Department of Internal Medicine, Pitié-Salpêtrière Hospital, Paris, France

J Cabane

A Michon

J-M Ziza

O Blétry

P Godeau

Department of

Rheumatology,

Bichat Hospital,

Paris, France

$P$ Bourgeois

M-F Kahn

Correspondence to: Dr Jean Cabane, Service de Médecine Interne 4, Hôpital de la Pitié, 87 Boulevard de l'Hôpital, 75013 Paris, France.

Accepted for publication 15 June 1989
Still's disease is a rare disorder of unknown origin characterised by high spiking fever, evanescent rash, and arthritis, with an afternoon exacerbation $^{1}$; the main biological feature is neutrophilic leucocytosis. ${ }^{2}{ }^{3}$ Other features may include splenomegaly, pleuritis, pericarditis, and hepatic abnormalities. Bywaters' first descriptions of adult Still's disease stated that the long term articular prognosis seemed good, with the exception of a possible ankylosis of the cervical spine. ${ }^{14}$ This optimistic view, shared by some authors, ${ }^{56}$ has been challenged by others. $^{2}$ 7-9

Although the first months of the disease are well known, characterised by great difficulties in controlling the inflammatory manifestations of this systemic disease, the long term prognosis of Still's disease remains unclear. Moreover, it is not known whether juvenile onset Still's disease and adult onset Still's disease evolve similarly.

Thus we selected out of our large series of patients with Still's disease those whose disease had been followed up for more than 10 years, in order to study the long term evolution and to compare patients with adult onset and juvenile onset Still's disease.

\section{Patients and methods}

During the past 20 years 65 patients fulfilling the American Rheumatism Association criteria for Still's disease ${ }^{3}$ were followed up at the Bichat and the Pitié-Salpêtrière Hospitals in Paris. We retrospectively reviewed the charts of 18 patients whose disease was diagnosed before 1 January 1978. All the features of Still's disease were compiled and follow up data were noted in detail. Telephone interviews and letters sent to the patients and their doctors ensured continuity of follow up. Ten (group 1) presented polyarthritis during childhood and had a new flare up at the adult stage. Eight (group 2) had Still's disease which began after the age of 15 . We studied the $x$ rays of symptomatic joints only.

The radiological joint lesions were categorised according to Björkengren et $a l^{10}$ as follows: narrowing of the articular space: $0=$ none, 1 =moderate, 2 =major, 3 =fusion; subchondral erosions: $0=$ none, $1=$ presence.

Figures 1 and 2 illustrate cases of juvenile and adult onset Still's disease.

\section{Results}

The table shows the clinical characteristics of the two groups. It should be emphasised that our series of patients with Still's disease comprised 65; selection eliminated comparable numbers of patients with adult and juvenile onset Still's disease who had been followed up for less than 10 years. No patient was excluded for other reasons. Thus the groups were as comparable as possible because no randomisation was applicable.

We expected that the evolution of the disease, the articular sequelae, or other characteristics would differ in these two groups. No differences were significant, however, except for the occurrence of three cases of amyloidosis in group 2 and none in group 1. Two of these cases of amyloidosis have been reported elsewhere. ${ }^{11}$

All patients had multiple flare ups of Still's disease requiring large doses of corticosteroids and were dependent on these drugs during the 


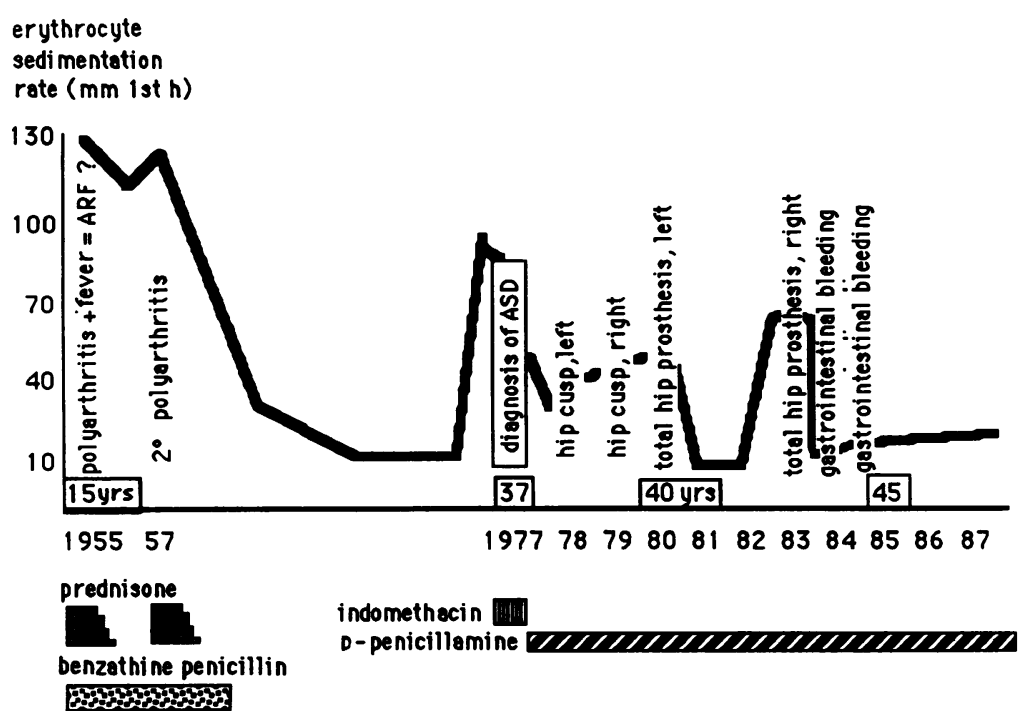

Figure 1: Evolution of Still's disease (SD) in a patient with adult onset disease. Note the rapid destruction of both hips from the date of the diagnosis. This patient had so-called 'acute rheumatic fever' (ARF) antecedents which might have represented the true beginning of his Still's disease. Insufficient data were available to resolve this question.

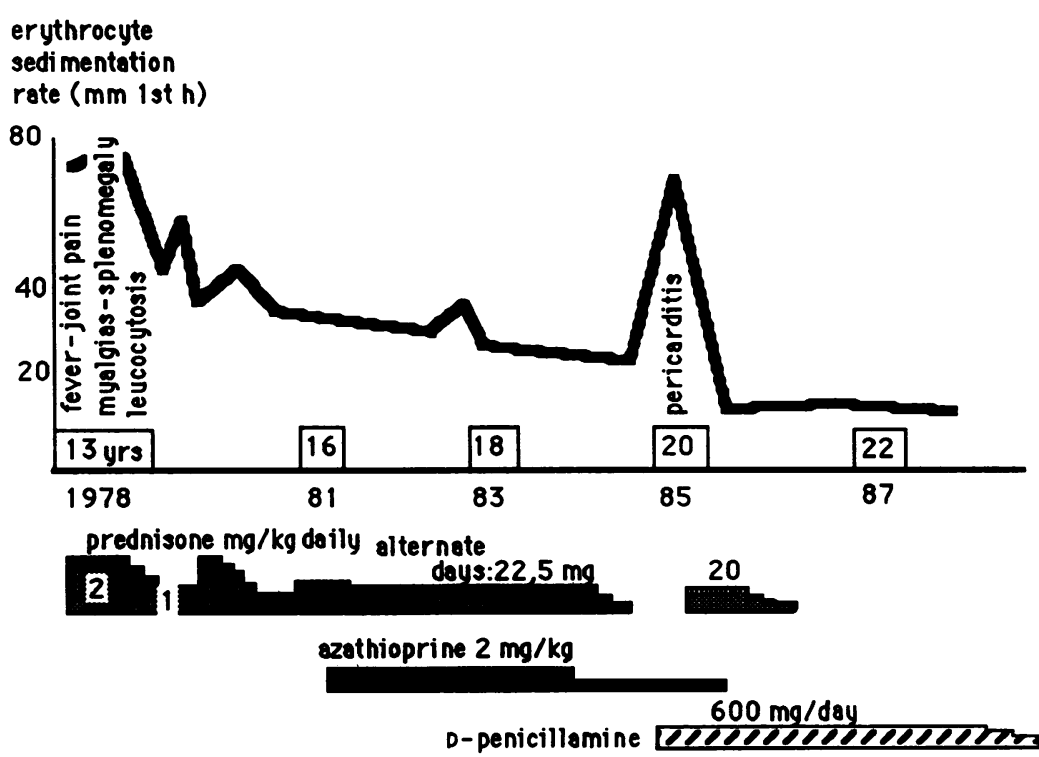

Figure 2: Evolution of Still's disease in a patient with juvenile onset. This patient had particularly few sequelae. first phase of the disease. The outcome at 10 years may be summarised as follows:

1. The appearance of sequelae was delayed for years in both groups. In group 1 only one patient showed any articular sequela before age 15. Figure 3a shows the evolution of articular damage between childhood and adulthood. In group 2 the joint destructions appeared also between one and eight years after the diagnosis.

2. The arthritis was difficult to control in both groups. In group 1 (10 patients with juvenile onset Still's disease) two patients still have persistent joint pain and inflammation. Both are being treated with corticosteroids; one of them is also taking methotrexate $7.5 \mathrm{mg} /$ week Eight patients are in clinical remission: two without any treatment, three with low dose corticosteroids, and three with other drugs (methotrexate $7.5 \mathrm{mg} /$ week or D-penicillamine $600 \mathrm{mg} /$ day or piroxicam $20 \mathrm{mg} /$ day). In group 2 (eight patients with adult onset Still's disease) two patients-one of whom died-developed renal insufficiency due to amyloidosis and one died from a digestive haemorrhage caused by amyloidosis. In another patient Still's disease remains active, requiring corticosteroids. Two have achieved a complete remission and take no treatment; three are pain free while taking prednisone $12 \mathrm{mg} /$ day or methotrexate $7.5 \mathrm{mg}$ weekly, or D-penicillamine $600 \mathrm{mg} /$ day respectively.

Overall, the joint lesions were common and devastating in both groups; hip lesions were the most serious. Only seven patients were free from hip pain. Nine patients had severe hip destruction requiring 13 total hip prostheses. Hip cups (three) gave poor results. Figures $3 a$ and $b$ show the patients' lesions. The wrist was injured in five patients (two had bilateral lesions), the tarsus in two, the knee in one, and the shoulder in one. It was of note that the finger joints were spared. Three patients have ankylosis of the cervical spine, including one with scoliosis of the entire spine due to the disease. One patient in group 2 underwent an arthrodesis of the foot. Multiple articular injections (corticosteroids, osmic acid) were given.

3. Iatrogenic complications occurred due to the high doses of anti-inflammatory drugs prescribed: cushingoid appearance (two); aseptic necrosis of the femoral head (one), of the lower extremity of the femur (one), and of the ankle (two); one patient bled from a gastroduodenal ulcer; and two patients in group 1 had severe growth sequelae.

4. The prognosis of the extra-articular lesions of Still's disease, principally the cardiac, cutaneous, and pleuropulmonary signs, was always good as they disappeared without any sequelae in all the patients. In particular, the pericarditis rarely recurred (and never more than once) and we did not see constrictive pericarditis, pleuropulmonary fibrosis, or scarring.

\section{Discussion}

No report compares the long term evolution of Still's disease in patients with juvenile onset and those with adult onset disease. Our study shows that the evolution is the same in all patients 


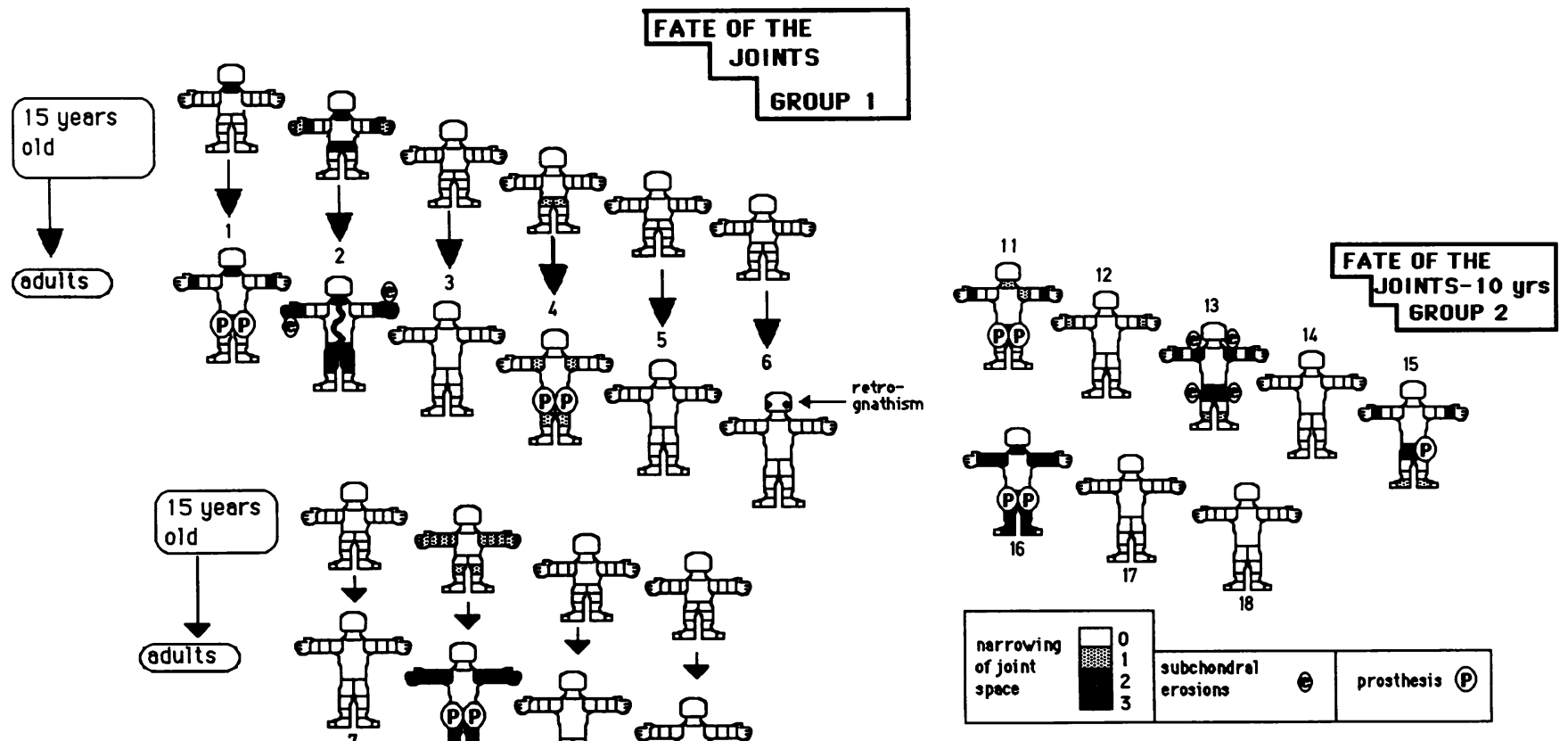

$(3 b)$

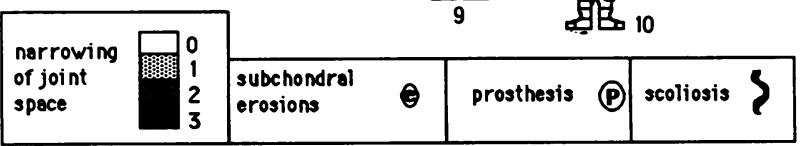

(3a)

Figure 3: (a) Long term (more than 10 years) fate of the joints of patients with juvenile onset Still's disease (10 patients whose Still's disease began before age 15: group 1). The figure shows for each patient the joint status at 15 years (top) and at the end of the follow up (bottom). Note that most of the patients had few or no sequelae of the disease at 15 years; the sequelae appeared later. Patient No 8, however, evolved as a continuum from the beginning and remission of the disease never occurred in this case. The narrowing of the joint space was coded according to Björkengren et al ${ }^{10}$ (see 'Patients and methods'). (b) Long term (more than 10 years) follow up data in patients with adult onset Still's disease. Note that patient No 12 had aseptic necrosis of both ankles and of the left knee. Patient No 14 died from digestive bleeding due to amyloidosis two years after the apparent onset of his disease; however, he had had two episodes of cryptogenic polyarthritis at 7 and 15 years. Patients 13 and 16 have had renal amyloidosis, which appeared respectively 6 and 11 years after the onset of Still's disease. Patient 16 died a few months later, but patient 13 is receiving haemodialysis.

regardless of age of onset. We note, however, that the three cases of secondary amyloidosis in our study belong to group 2 (those with adult onset).

According to our data, the articular sequelae take five to seven years to appear. As the disease commonly begins in late childhood the follow up time is generally insufficient to observe them as children.

We found that the overall long term prognosis of Still's disease is clearly good for the systemic manifestations, but not for the articular ones: severe joint lesions do occur and often leave the patients with severe sequelae. The incidence of hip injury is striking: 13 total hip prostheses had to be placed before age 45 in seven patients. This agrees with other series of juvenile arthritis ${ }^{7}$ and of adult Still's disease. ${ }^{2} 89$

No treatment was effective in preventing those long term complications. Clearly, the disease has a strong (but not obligatory) predilection for the joints and, in particular, the hips. Once the destructive process has begun the injury worsens rapidly, requiring a prosthesis on average five years after the first $x$ ray signs. As our patients were treated with the maximum tolerable doses of corticosteroids, aspirin, and non-steroidal anti-inflammatory drugs, however, the iatrogenic effects were common. None of the anti-inflammatory drugs used was effective in preventing long term damage of the joints. We are now experimenting with innovative drug regimens, such as low dose methotrexate, ${ }^{12}$ which may provide better control of Still's disease in the long term. We are also considering early synoviortheses for the affected joints in order to prevent long term destruction.

We are grateful to the doctors of the Pitié and Bichat Hospitals for their help in the care of the patients, and to Celie Cabane and Edward Sykes for their help in translating the manuscript.

Bywaters E G L. Still's disease in the adult. Ann Rheum Dis 1971; 30: 121-33.

2 Wouters J M G W, van de Putte L B A. Adult-onset Still's disease; clinical and laboratory features, treatment, and progress of 45 cases. $Q \mathcal{F}$ Med 1986; 61: 1055-65.

3 Reginato A J, Schumacher H R, Baker D G, O'Connor C R Ferreiros J. Adult onset Still's disease: experience with 23 patients and literature review with emphasis on organ failure. Semin Arthritis Rheum 1987; 17: 39-57.

4 Isdale I C Bywaters E G L. The rash of rheumatoid arthritis and Still's disease. O F Med 1956; 25: 377-87.

5 Calabro J J, Burnstein S L, Staley H L, Marchesano J M

Prognosis in juvenile rheumatoid arthritis: a fifteen-year Prognosis in juvenile rheumatoid arthritis: a fifteen-year

6 Esdaile J M, Tannenbaum H, Hawkins D. Adult Still's disease. Am F Med 1980; 68: 825-30.

7 Hanson V, Kornreich H, Bernstein B, Koster King K, Singsen B. Prognosis of juvenile rheumatoid arthritis. Arthritis Rhewm 1977; 20: 279s-84s.

8 Elkon K B, Hughes G R V, Bywaters E G L, et al. Adult onset Still's disease: twenty years follow-up and further studies in patients with active disease. Arthritis Rheum 1982; 25: $647-54$.

9 Larson E B. Adult Still's disease, evolution of a clinical syndrome and diagnosis, treatment and follow-up of 17 pyndrome and diagnosis, treatment and follow-

10 Björkengren A G, Pathria M N, Sartoris D J, et al. Carpal alterations in adult-onset Still's disease, juvenile chronic alterations in adult-onset Still's disease, juvenile chronic arthritis and adult-onset rheumatoid

11 Vigneron A M, Kaplan G, Labrousse C, Leroux-Robert C René E, Kahn M F. Amylose au cours de la maladie de Still de l'adulte. A propos de deux observations. Ann Med Interme (Paris) 1986; 137: 406-8.

12 Bourgeois P, Kahn M F. Low dose methotrexate for Still's disease in adults. [Abstract]. Clinical and Experimental Rheumatology 1987; 5 (suppl 2): 123 